\title{
The effect of limbal mesenchymal stem cell secretome eye drops for wound healing in pseudomonas aeruginosa keratitis
}

\author{
Afif Maulana Firmansyah ${ }^{1,2}$, Ismi Zuhria ${ }^{1,2}$, Nurwasis Nurwasis ${ }^{1,2}$ \\ Email: afif.maulana.f@gmail.com; nurwasis78@gmail.com \\ ${ }^{1}$ Department of Ophthalmology, Dr. Soetomo General Hospital, Surabaya 60286, Indonesia \\ ${ }^{2}$ Faculty of Medicine, Universitas Airlangga, Surabaya 60286, Indonesia
}

\begin{abstract}
Background: To investigate the effects of limbal mesenchymal stem cell (L-MSCs) secretome on the cornea surface for balancing TNF- $\alpha$ and IL-10 in animal models of pseudomonas aeruginosa keratitis in wound healing process.

Method: Animal models have performed a $2 \mathrm{~mm}$ long incision with a scratching technique on the central cornea. Then induction of keratitis is inoculated with $1.0 \times 10^{4} \mathrm{CFU}$ of Pseudomonas aeruginosa $5 \mu \mathrm{L}$ of PBS on the cornea surface. The study subjects consisted of 2 groups. The first group was given the antibiotic Levofloxacin $0.5 \% 1$ drop every 6 hours for 5 days. The second group was given Levofloxacin $0.5 \% 1$ drop after that the next 5 minutes given L-MSCs secretome 1 drop every 6 hours for 5 days. After treatment the rat were enucleated and corneal tissue was given immunohistochemistry staining of cytokines TNF- $\alpha$ and IL-10 for analyzed.

Result: After 5 days of L-MSCs secretome therapy, results expression of TNF- $\alpha$ was not decreased with treatment LMSCs. The results expression of IL-10 was not increased with treatment L-MSCs.

Conclusion: Therapy of L-MSCs secretome was not effected to expression of TNF- $\alpha$ and IL-10, but clinically improved keratitis condition.
\end{abstract}

Keywords: limbal mesenchymal stem cell, secretome, keratitis, pseudomonas aeruginosa, TNF- $\alpha$, IL-10

\section{Introduction}

Keratitis caused by bacteria is a case that frequently happened. Pseudomonas aeruginosa is the second most commonly microorganism that causes keratitis. The flagellin and toxin material that produced by $\mathrm{P}$. aeruginosa causing a severe inflammation (O'Callaghan et al, 2019). Although antibiotic therapy can kill bacteria quickly, but the damage to the cornea will continue, because the toxin material that produced by the bacteria, triggers a sustainable inflammatory response. The formation of scar tissue in the cornea is a chronic complication that can happen and will interfere the patient's vision. It related to poor wound healing process (Ismail et al, 2018). Corneal wound healing is determined by pro-inflammatory cytokines, anti-inflammatory cytokines or the balance of two cytokines. The increase of pro-inflammatory cytokines such as TNF- $\alpha$, IL-6 and IL-8 in the early phase of the wound healing phase. Anti-inflammatory cytokines such as IL-10 and IL-4 are needed to control pro-inflammatory cytokines so can reduce the occurrence process of the of the cicatrix tissue (Tang, 2016). For that condition, additional therapies need to helping the wound healing process while reducing the occurrence of long-term inflammation and to reduce the risk of cicatrix tissue. The aim of this study is to analyze the therapeutic effect of eyedrops L-MSCs secretome in mouse eyes that induced become Pseudomonas aeruginosa keratitis by evaluating the inflammatory levels based on cytokine expressions TNF$\alpha$ and IL-10 on the surface of the cornea. 


\section{Material and Method}

\subsection{Induction of animal model bacterial keratitis}

Before induction 14 rats with bacterial keratitis, examination the surface of the eyeball. Rats were anesthetized with injections of ketamine and xylazine (ketamine $40 \mathrm{mg} / \mathrm{ml}$, xylazine $20 \mathrm{mg} / \mathrm{ml}$ ) intramuscularly. Corneal defects are made using scratch techniques in three places on the central cornea with a length about $2 \mathrm{~mm}$. Induction of bacterial keratitis dripping with $5 \mu$ from the suspension of $P$. aeruginosa containing $10^{4} \mathrm{CFU}$. The induced rats are maintained with standard cage conditions that have been set by the laboratory of the Faculty of Veterinary Medicine, Universitas Airlangga. The rats randomly divided into group K1 and group K2. Two days after induction, the surface of the eyeball was examined.

\subsection{Limbus mesenchymal stem cell metabolite (L-MSCs) secretome}

Corneosclera tissue was obtained from the eyes of a healthy rats with weight 250-300 grams. Retrieval was done by aseptic surgery in the animal laboratory stem cell research and development centre, Universitas Airlangga based on a protocol developed by Chen, et al. (2011). Rats were anesthetized with injections of ketamine and xylazine (ketamine $40 \mathrm{mg} / \mathrm{ml}$, xylazine $20 \mathrm{mg} / \mathrm{ml}$ ) intramuscularly. The rats that anesthetized were placed on the operating table and installed sterile cloth. Eyeballs are disinfected with $5 \%$ iodine povidone and rinsed with balance salt solution. Conjunctival peritomy $360^{\circ}$ continued with the retrieval of corneosclera tissue $360^{\circ}$ full thickness consisting of $1 \mathrm{~mm}$ peripheral cornea and $3 \mathrm{~mm}$ limbus. The tissue that has been retrieval washed using phosphate buffer saline (PBS) 3 times and stored in a transport media consisting of DMEM $+200 \mathrm{U} / \mathrm{ml}$ penicillin $-200 \mathrm{U} / \mathrm{ml}$ streptomycin with temperature $4{ }^{\circ} \mathrm{C}$. The sample was sent to the stem cell processing laboratory for $<24$ hours.

The cell was obtained from the stem cell laboratory, Universitas Airlangga. To obtained secretome, amount of $5 \times 103$ cell/well of L-MSC was treated treated for 24 hours using media composed of $\alpha$-MEM, $1 \%$ amphotericin B, $1 \%$ NEAA, $1 \%$ penicillin-streptomycin, and $2 \% \mathrm{FBS}$ ). The secretome was collected and filtered using $0.45 \mathrm{um}$ millipore, the osmolarity and acidity were adjusted for $270-300 \mathrm{mOsm} / \mathrm{L}$ and $7.2-7.5$, respectively. The secretome was packaged into single dose application in sterile Eppendorf tube and stored at $-20^{\circ} \mathrm{C}$ until further application

\subsection{Animal model treatment}

Fourteen wistar rats was induced to keratitis, after 48 hours was observed and divided to 2 groups. The first group was given the antibiotic Levofloxacin $0.5 \% 1$ drop every 6 hours for 5 days. The second group was given Levofloxacin $0.5 \% 1$ drop then the next 5 minutes given L-MSCs secretome 1 drop every 6 hours for 5 days. After the treatment, the mice were enucleated and the corneal tissue of the mice were given staining of immunohistochemistry cytokines TNF- $\alpha$ and IL-10 for analysis. On the seventh day, examining the superficial condition of the eyeball, then terminating the animal model and enucleated for staining of immunohistochemistry antibodies cytokines TNF- $\alpha$ and IL-10.

\section{Results}

3.1. Limbal mesenchymal stem cell secretome promote wound healing of keratitis P. aeruginosa

Keratitis was occurred in all rats 48 hours post induction. After that all rats given treatment according their groups. Clinical improvements seen in all rats, but in group K1 still showed keratitis sign like infiltrate and fluorescein test positive. In the group K2 was showed significant improvement. There is dropout of 2 samples in the group K1 and 1 sample in the group K2 during this study. 


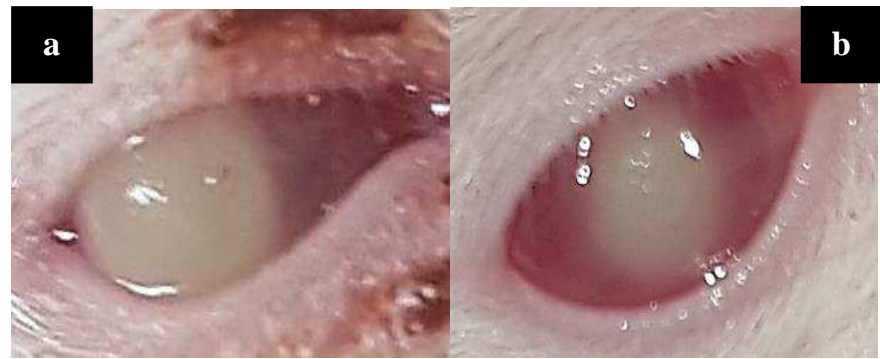

Fig. 1. Clinical picture of the keratitis on the animal model. After observation for $2 \times 24$ hours post induction. (a) Group K1 (Antibiotic). (b) Group K2 (Antibiotic + L-MSCs secretome).

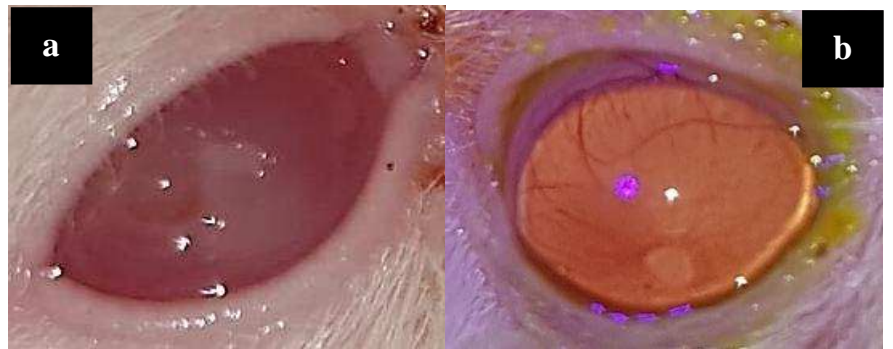

Fig. 2. Clinical overview of the animal model after 5 days of treatment. Clinical improvements seen in both groups. (a) Group K1 (Antibiotics). (b) Group K2 (Antibiotics + LMSCs secretome). During the study there are dropout of 2 samples in the K1 group and 1 sample in the $\mathrm{K} 2$ group.

3.2. Results of TNF- $\alpha$ expression in treatment with antibiotic and L-MSCs secretome eye drops to animal model keratitis $P$. aeruginosa.

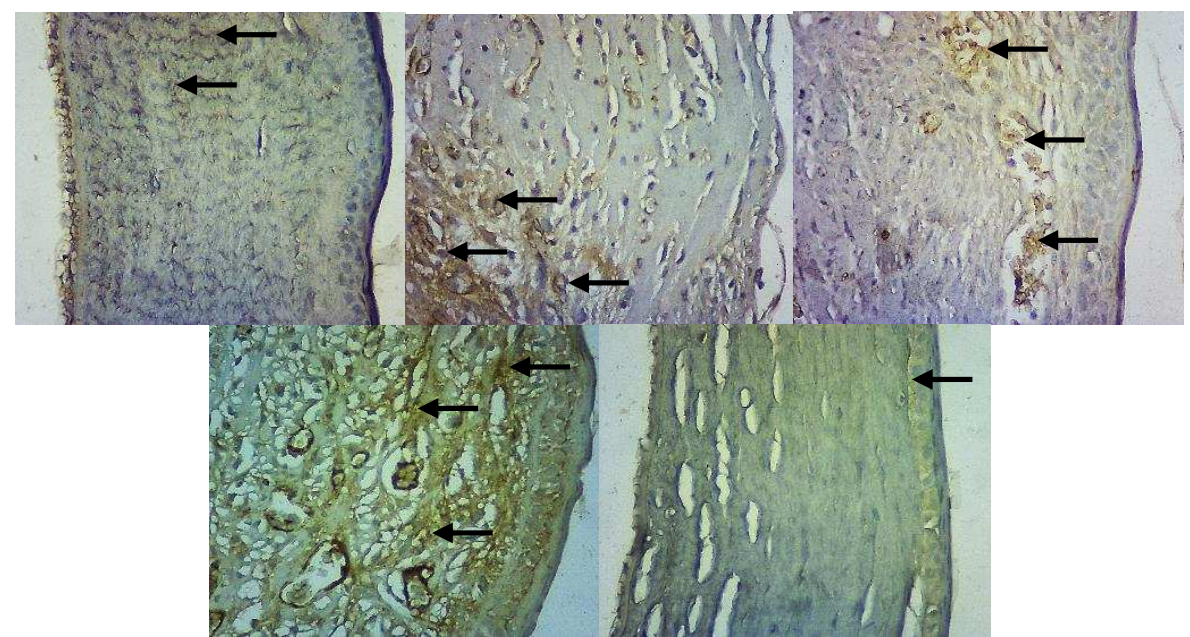

Fig. 3. Expression of TNF- $\alpha$ antibodies in the K1 group (antibiotic) was showed by arrows on cells that are chromogenic brown (immunohistochemistry staining, zoom in 400x). 


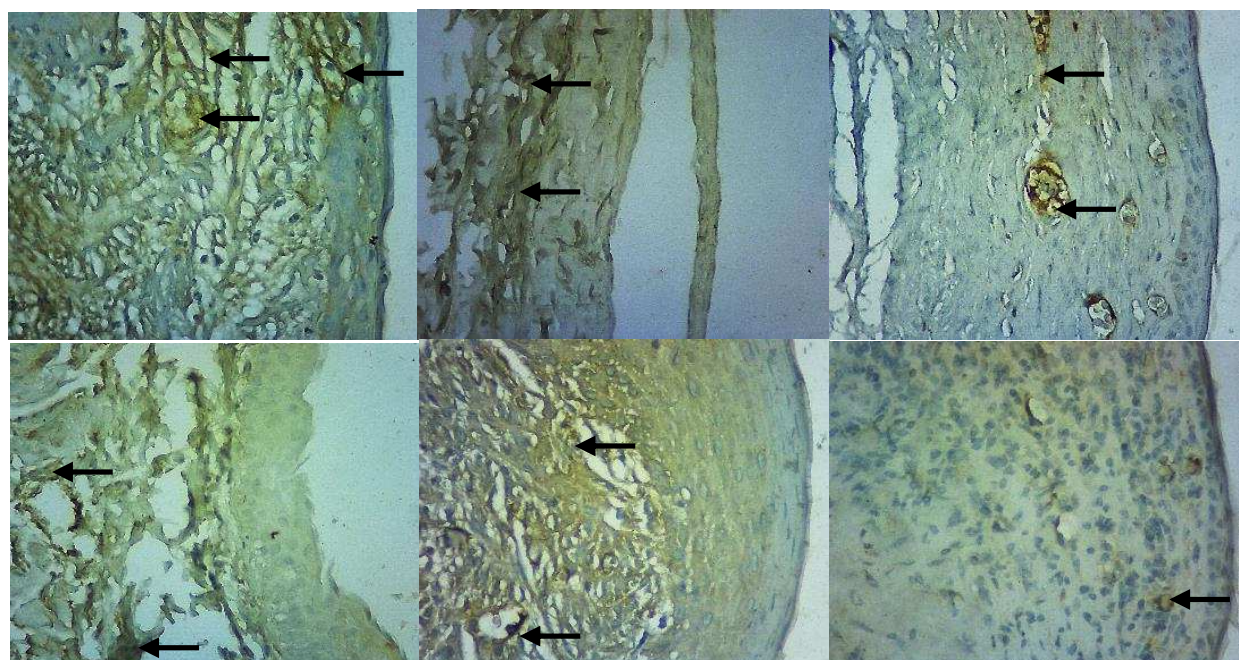

Fig. 4. Expression of TNF- $\alpha$ antibodies in the K2 group (antibiotic + LMSCs secretome) was showed by arrows on cells that are chromogen brown (immunohistochemistry staining, zoom in 400x).

In this study has been done immunohistochemistry staining of TNF- $\alpha$ antibodies and evaluation with a 400x enlargement microscope after the 7th day of treatment. In the antibiotic group, the average score is 4.28 , with the lowest score is 1.8 and the highest is 7.6. While in the group of Antibiotic + LMSCs secretome the average score is 3.47, with the lowest score is 1.4 and the highest score is 8.4 . By the TNF- $\alpha$ expression average scores, the antibiotic group + LMSCs secretome was higher than the antibiotic group. The Independent $\mathrm{T}$-Test showed the expression of $\mathrm{TNF}-\alpha$ in the antibiotic group with the antibiotic group + LMSCs secretome had no significant difference.

Table 1. TNF- $\alpha$ expression mean scores

\begin{tabular}{lccc}
\hline \multicolumn{1}{c}{ Group } & $\mathrm{n}$ & $\begin{array}{c}\text { TNF- } \alpha \text { expression } \\
\text { mean } \pm \text { SD }\end{array}$ & T-Test (1-tailed) \\
\hline Antibiotic & 5 & $4.28 \pm 2.32$ & .354 \\
Antibiotic + LMSCs Secretome & 6 & $3.47 \pm 2.70$ & \\
\hline
\end{tabular}

3.3. Results of IL-10 expression in treatment with antibiotic and L-MSCs secretome eye drops to animal model keratitis $\mathrm{P}$. aeruginosa.

And evaluation under the microscope with 400x enlargement, the results of IL-10 expression in the antibiotic group with an average score is 5.16, with the lowest score is 1.6 and the highest score is 9.6. While in the group of antibiotic + LMSCs secretome an average score is 7.67, with the lowest score is 4 and the highest score is 11.4. By the IL-10 expression average score, the antibiotic group + LMSCs secretome was higher than the antibiotic group. The Independent T-Test showed the expression of IL-10 in the antibiotic group with the antibiotic group + LMSCs secretome had no significant difference. 


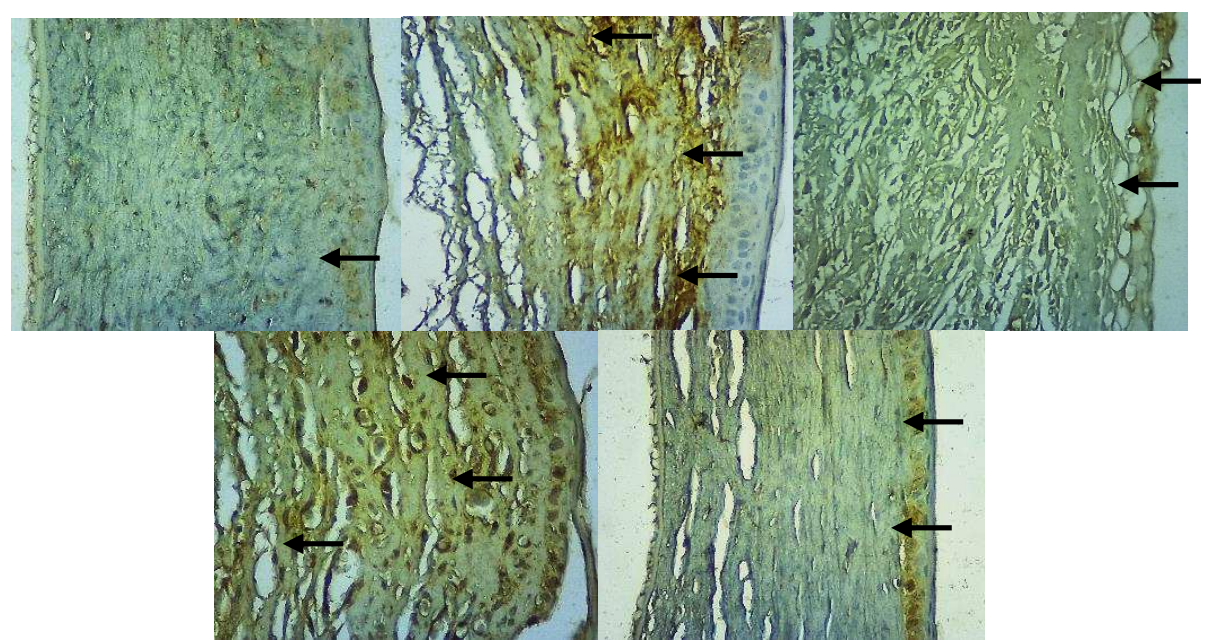

Fig. 5. Expression of IL-10 antibodies in the K1 group (antibiotic) was showed by arrows on cells that are chromogen brown (immunohistochemistry staining, zoom in 400x).

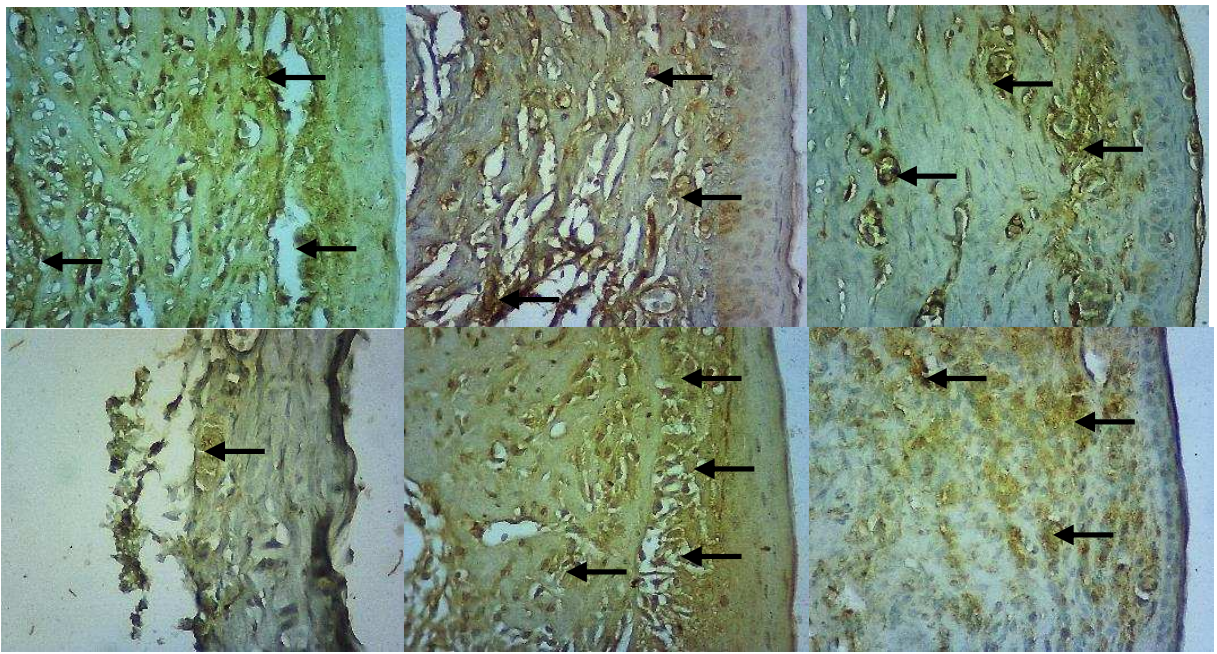

Fig. 6. Expression of IL-10 antibodies in the K2 group (antibiotic + LMSCs secretome) was showed by arrows on cells that are chromogen brown (immunohistochemistry staining, zoom in 400x).

Table 2. IL-10 expression mean scores

\begin{tabular}{lccc}
\hline Group & $\mathrm{n}$ & $\begin{array}{c}\text { IL-10 expression } \\
\text { mean } \pm \text { SD }\end{array}$ & T-Test (1-tailed) \\
\hline Antibiotic & & 5 & $5.16 \pm 3.39$ \\
Antibiotic + LMSCs Secretome & 6 & $7.67 \pm 2.74$ & .153 \\
\hline
\end{tabular}




\section{Discussion}

Keratitis is an inflammation of the corneal tissue caused by infection. Pseudomonas aeruginosa is the most common microorganism that causes keratitis. Because the infection process develops very quickly and can cause intraocular infection (endophthalmitis) and corneal perforation. Furthermore, the endotoxin produced by P. aeruginosa causes prolonged inflammation even though antibiotic therapy can quickly kill bacteria. Scar tissue formation on the cornea as a chronic complication that can occur, which it will interfere with the patient's vision. (O'Callaghan et al, 2019; Tang, 2016)

This study is the first study that analyse the treatment of LMSCs secretome to animal models of keratitis caused by P. aeruginosa, based on the expression of the pro-inflammatory cytokine TNF- $\alpha$ and the antiinflammatory IL-10 on the cornea. Our study same with previous studies which the treated of the antibiotic levofloxacin $0.5 \%$ post-induction of keratitis for 5 days can reduce the infection process, showed by improvements of clinical condition the groups of animal model. (Kowalski et al, 2010; Darusman et al, 2012; Tajima et al, 2015) In the antibiotic group still showed the signs of keratitis compared to the group of antibiotics and L-MSCs secretome which is more minimal the signs of keratitis.

This study analysed the effect of limbus MSCs secretome on decreased TNF- $\alpha$ expression. In this study, the antibiotic group with the antibiotic group + limbus MSCs secretome had no significant difference. In the previous studies analyzed on corneal alkaline chemical trauma which was treated with subconjunctival injection of bone marrow MSCs (BMMSCs)showed a reduction of the TNF- $\alpha$ cytokine compared to the control group. Previous studies have also demonstrated the ability of MSCs to inhibit the production of the pro-inflammatory cytokine TNF- $\alpha$ by macrophages. (Yao et al, 2012) Another study about treatment of placental MSCs secretome on the skin of rats. The results of this study showed an increase in TNF- $\alpha$ expression significantly in the control group. Histologically it showed a decrease in PMN and monocyte activity in the treatment group compared to the control group. So it can be concluded that placental MSCs metabolites are effective and efficient for wound healing. (Purwati et al, 2019) One research that similar with our research was examined the administration of BM-MSCs in teratogenic animal models. The results of this study indicate that the giving of BM-MSCs has not been able to reduce the expression of TNF- $\alpha$. The inability to decrease TNF- $\alpha$ in this study was caused by only one day of therapy, so that the BM-MSCs had not been able to work optimally in reducing TNF- $\alpha$ expression. (Madyawati et al, 2015; Kresno, 2013)

The next parameter that analyzed in this study about the effect of the limbus MSCs secretome on increased IL-10 expression. In this study, it was found increase of IL-10 expression in the antibiotic group + limbus MSCs was no significant. Another study on BM-MSCs is administration in animal models of acute liver failure through the induction of IL-10 secretion. The increase in IL-10 will reduce the levels of the inflammasome NLRP3-caspase-1 thereby reducing pyroptosis and in the repair of acute liver failure. (Wang et al, 2017) Another study about treatment of placental MSCs secretome on the skin of rats showed increasing in IL-10 antibiotic with L-MSCs group. (Purwati et al, 2019)

\section{Conclusion}

So it can be concluded that the addition of L-MSCs secretome was not effected to expression of TNF- $\alpha$ and IL-10, but clinically improved keratitis condition.

\section{Acknowledgements}

None

\section{Conflict of Interest}

Nil 


\section{References}

Darusman KR., Sitompul R., Susiyanti M., Sudarmono P. \& Estuningtyas A. 2012. Efficacy of Topical Levofloxacin $0.5 \%$ in Treating Levofloxacin-resistant Pseudomonas aeruginosa-induced Keratitis. AsiaPasific Journal of Ophthalmology, 1(2), pp 120-125.

Ismail KA., Hawash YA., Khalifa AM. \& Khalifa OM. 2018. Role of Stem Cells in Treatment of Acanthamoebic Corneal Ulcer. Current Trends Biomedical Engineering \& Biosciences, 17(3), pp 1-8.

Kresno, SB. 2013. Imunologi. Diagnosis dan Prosedur Laboratorium, Jakarta: Badan Penerbit FKUI, ed 5.

Kowalski RP., Romanowsi EG., Mah FS., Shanks RMQ. \& Gordon YJ. 2010. Topical Levofloxacin 1.5\% Overcomes in Vitro Resistance in Rabbit Keratitis Models. Acta Ophthalmol, 88(4), pp 1-14.

Madyawati SP., Rimayanti, Widjiati \& Achmad AB. 2015. Efektivitas Terapi Rat Bone Marrow Mesenchymal Stem Cell pada Tikus Model Teratogenic Particulate Matter Terhadap Ekspresi TNF- $\alpha$, Bax, dan Bcl-2 plasenta. Jurnal Kedokteran Hewan, 9(1), pp 1-4.

O’Callaghan R., Caballero A., Tang A. \& Biederman M. 2019. Pseudomonas aeruginosa Keratitis: Protease IV and PASP as Corneal Virulence Mediators. Microorganism 7, 281, pp. 1-17.

Purwati, Listiawan MY., Iswanda PA., Rantam FA., Susilowati H., Hendrianto E. et al. 2019. Pre-Clinical Trial Stem Cell Metabolites Derived from Placenta for Wound Healing. Biochem. Cell. Arch., 19, pp 4833-4838.

Tajima K., Miyake T., Koike N., Hattori T., Takahashi H., Matsumoto T. et al. 2015. Two Different Concentrations of Topical Levofloxacin for the Treatment of Multidrug-Resistant Pseudomonas Aeruginosa Keratitis. Journal of Ocular Pharmacology and Therapeutics, 00(00), pp 1-6.

Tang YH. 2016. Mesenchymal Stem Cell Therapy in Skin Wound Healing. Trauma \& Acute Care, 1, pp 1-2.

Wang J., Ren H., Yuan X., Ma H., Shi X. \& Ding Y. 2017. IL-10 Secreted by Mesenchymal Stem Cells Attenuates Acute Liver Failure through Inhibiting Pyroptosis. Hepatology Research, 48(3) pp 194-202.

Yao L., Li Z., Su W., Li Y., Lin M., Zhang W. et al. 2012. Role of Mesenchymal Stem Cells on Cornea Wound Healing Induced by Acute Alkali Burn. PLoS ONE, Vol. (2), pp 1-7. 